\title{
MODELOS DE HISTÓRIA NATURAL: AS IMAGENS DOS BUSTOS RACIAIS NOS MUSEUS ESCOLARES
}

\author{
Felipe Rodrigo Contri Paz \\ Universidade Federal do Rio Grande do Sul \\ felipecontripaz@hotmail.com
}

\begin{abstract}
RESUMO
Em levantamento realizado em museus localizados em espaços escolares na Região Metropolitana de Porto Alegre localizou-se a presença de imagens representativas dos diferentes tipos raciais humanos no museu escolar do antigo Instituto São José - La Salle/Canoas (RS) e no Museu Metodista de Educação do Colégio Americano (RS). O objetivo deste trabalho é verificar e analisar os diferentes usos destes materiais no ensino, e suas possíveis relações com o método intuitivo. Problematizando o giro conceitual destes modelos de gesso na história da educação brasileira, evidencia-se que estes foram tendência de ensino sobre a espécie humana e suas diferentes raças, bem como aportes de teorias racialistas correntes na época. Como resultados parciais, descobriu-se que estes bustos também podem ser verificados nos acervos de escolas de grandes centros como o Rio de janeiro e Lisboa. No caso português essas peças remontam o século XIX. No Rio de Janeiro, o Colégio Pedro II, considerado um modelo a ser seguido pelas demais escolas nacionais, adquiriu peças semelhantes entre as décadas de 1920 e 1930, o que demonstra certa tendência do uso destes objetos no ensino escolar.
\end{abstract}

Palavras-chave: Museus Escolares. Método Intuitivo. Objetos de ensino. Modelos de História Natural.

\section{NATURAL HISTORY: THE IMAGES OF RACIAL BUSTS IN SCHOOL MUSEUMS}

\begin{abstract}
In a survey conducted in museums located in school spaces in the metropolitan area of Porto Alegre, found the presence of representative images of different human racial types in the school museum of the former Institute of São José - La Salle / Canoas (RS) and the Methodist Museum American College of Education (RS). The objective of this work is to verify and analyze the different uses of these materials in teaching, and their possible relationships with the intuitive method. Questioning the conceptual turning these plaster models in the history of Brazilian education, it is evident that these were educational trend of the human species and its different races, as well as contributions from current racialist theories at the time. As partial results, it was found that these busts can also be checked in the collections of schools in large cities such as Rio de Janeiro and Lisboa. In the Portuguese case these pieces date back to the nineteenth century. In Rio de Janeiro, the College Pedro II, considered a model to be followed by other national schools, purchased parts similar between the 1920 and 1930s, which shows a tendency of using these objects in school education.
\end{abstract}

Keywords: School Museum. Intuitive Method. Teaching objects. Natural history models. 


\title{
HISTÓRIA NATURAL: LAS IMAGENES DE LOS BUSTOS RACIALES EN LOS MUSEOS ESCOLARES
}

\begin{abstract}
RESUMEN
En una encuesta realizada en museos ubicados en espacios escolares en la región metropolitana de Porto Alegre se encuentra la presencia de imágenes representativas de diferentes tipos raciales humanos en el museo de la escuela del antiguo Instituto de San José - La Salle / Canoas (RS) y el Museo Metodista de Educación el Colegio americano (RS). El objetivo de este estudio es verificar y analizar los diferentes usos de estos materiales en la enseñanza, y su posible relación con el método intuitivo. El cuestionamiento de la inflexión conceptual estos modelos de yeso en la historia de la educación brasileña, es evidente que ellos estaban enseñando tendencia de la especie humana y sus diferentes razas, así como las contribuciones de las teorías raciales actuales en el momento. Como resultados parciales, se encontró que estos bustos también se pueden verificar en las colecciones de las escuelas en las grandes ciudades como Río de Janeiro y Lisboa. En el caso portugués estas piezas datan del siglo XIX. En Río de Janeiro, el Colegio Pedro II, considerado como un modelo a seguir por otras escuelas nacionales, comprar piezas similares entre el 1920 y 1930, lo que muestra una tendencia de la utilización de estos objetos en la enseñanza escolar.
\end{abstract}

Palabras clave: Escuela de Museos, método intuitivo, objetos de educación, modelos de la historia natural.

\section{INTRODUÇÃO}

O presente estudo aborda a temática dos museus escolares em relação com os usos pedagógicos dos recursos visuais para o ensino dos tipos humanos. A pesquisa da dissertação, ora em processo de escrita, originou-se no Projeto de Pesquisa Museu no espaço escolar: de laboratório de aprendizagem à musealização contemporânea (Rio Grande do Sul, século XX) que objetivou mapear os museus escolares em relação com o método Lição de Coisas. A partir desse levantamento, foi identificado no museu escolar do antigo Instituto São José atual La Salle/Canoas (RS) - e no Museu Metodista de Educação do Colégio Americano inúmeros objetos de finalidade pedagógica ligados ao ensino dos tipos raciais humanos, principalmente imagens. As imagens das quais abordarei neste trabalho, em específico, serão os bustos raciais, materiais feitos em tamanho natural, compostos de papel machê, que circulavam dentre as mais variadas disciplinas no que tange ao ensino dos tipos raciais humanos.

O objetivo deste trabalho é verificar e analisar a utilização destes no ensino, e suas possíveis relações com o método intuitivo. Este estudo discute sobre a utilização destes modelos de História natural, com vistas a aproximar os alunos dos estudos racialistas. Problematizando o giro conceitual destes modelos na história da educação brasileira 
evidencia-se que estes foram tendência de ensino sobre a espécie humana e suas diferentes raças, bem como aportes de teorias racialistas correntes na época.

Assim, torna-se necessário um breve histórico para compreendermos como estes objetos ficaram frequentes em escolas normalistas e secundárias. Desse modo, abordo o surgimento dos museus escolares e do método Intuitivo, que visava ampliar os estudos dos educandos através dos sentidos, através do contexto de transição dos séculos XIX e XX. Em um segundo momento do texto discorro sobre o histórico de utilizações destes bustos raciais, passando pelos institutos científicos e museus de História natural até a entrada junto aos currículos escolares. Por fim, foco atenções aos bustos do museu do Instituto São José - atual La Salle Canoas (RS) e do museu do Colégio Americano e suas relações com a metodologia dos sentidos.

\section{AS IMAGENS QUE EDUCAM: O MÉTODO INTUITIVO E O CONTEXTO EDUCACIONAL}

O século XIX foi marcada por inúmeras mudanças sociais, políticas, culturais e tecnológicas em âmbito internacional. As unificações de Itália e Alemanha, a abolição da escravidão negra no Brasil, as revoluções liberais pela América e Europa, além dos avanços tecnológicos tais como o telefone, o automóvel, a locomotiva, o aprimoramente das câmeras fotográficas e o projetor de cinema ou cinematógrafo promoveram mudanças importantes na vida social dos países envolvidos. Esse turbilhão de novidades não deixaria de influenciar todos os estamentos da vida social dos países modernos ou em processo de modernização.

Assim, a própria educação, através de intelectuais das mais diversificadas áreas, era repensada com a finalidade de modificar os modos de ensino-aprendizagem, buscando um saber menos atrelado a memorialização e aos livros teóricos. No seio destas discussões, pensadores europeus e americanos iniciaram a aplicação do método intuitivo. Este método, também conhecido como Lições de Coisas buscava através de uma série de objetos e práticas promover a vivência dos alunos com seus objetos de conhecimento. Assim, para aprender sobre o reino vegetal o aluno visualizava e tocava uma planta. Na ausência desta, uma réplica era prontamente utilizada na substituição para o aluno sentir seu cheiro, visualizar suas formas, sentir suas texturas. De início esta metodologia ficou mais restrita aos conhecimentos das ciências exatas, no entanto, logo ampliaria-se para as demais ciências e disciplinas. 
No entanto este método não é uma invenção da transição dos séculos XIX e XX. O Método Intuitivo remonta origens teóricas no empirismo de John Locke (1632-1704) e Francis Bacon (1561-1626), onde o conhecimento é construído a partir da experiência sensorial, e não em ideias inatas sobrepostas. Sob este viés o ensino não pode ser transmitido, mas sim constantemente construído e aprimorado, essencialmente de forma experiencial.

Outro importante pensador empírico que inspirou a criação do Método Intuitivo foi David Hume (1711-1776). Filósofo, ensaísta e historiador nascido na Escócia ficou célebre por seu empirismo radical, que qualificava o homem como um animal experimental por natureza. Em sua obra “Investigação acerca do entendimento humano (1748)”, Hume analisa a fonte do conhecimento humano, buscando uma "geografia mental", onde pode mapear os caminhos da mente até o entendimento (VALDEMARIN, 2004).

O Método Intuitivo, nutrindo-se de fontes empíricas e sensitivas, foi pensado com a finalidade de romper com as metodologias de ensino ainda provenientes da Escolástica, essencialmente livresca e memorialística. Evidentemente que as teorias empiristas não foram transportadas em caráter integral para o ensino escolar. Há sim, toda uma adaptação desse veio intelectual para o ambiente de ensino formal.

O método intuitivo reporta-se epistemologicamente ao empirismo, teoria do conhecimento formulada por Francis Bacon e John Locke no século XVII e, posteriormente, transposta a uma formulação educacional que assume a forma de veiculação através de alguns manuais pedagógicos, editados na Europa e nos Estados Unidos e traduzidos para diversos outros países, incluindo o Brasil. (POSSAMAI, 2012, p. 3).

A obra máxima da Metodologia Intuitiva é Primary Object Lessons, lançado originalmente no ano de 1861. Nesses escritos o autor expõe os princípios da metodologia, colocando nos sentidos a chave para o entendimento e aprendizagem. A observação elevada a maior das qualidades sensoriais a serem trabalhadas pelo professor no aluno.

Para o autor americano, a diferença entre observar e meramente enumerar ou descrever coisas e objetos consiste em despertar o interesse da criança por meio de perguntas que propiciem oportunidade para o exercício do julgamento, instruindo pelas próprias coisas e não acerca das coisas. (VALDEMARIN, 2004, p. 120).

Para atender a tal missão, o manual de Calkins era constituído da forma socrática, em perguntas e respostas que visavam a trabalhar a observação visual, experimentação e a realidade próxima (AURAS, 2007). Assim, os sentidos seriam o canal de comunicação entre o sujeito e os objetos de conhecimento. Então se tornava imperial que para uma valorização da educação dos jovens, não apenas a escola, mas também a família e comunidade tratassem de exercitar o espírito observador. Estes deveriam agir como verdadeiros tutores, trabalhando no 
surgimento de situações-problema, onde os indivíduos pudessem se portar diante do desafio proposto. O manual ainda prescrevia para os professores o maior cuidado em sua didática, aprimorando as experiências dos educandos com as cores, formas, medidas, tamanhos, bem como práticas do desenho, estudos do corpo humano e educação moral. Deste modo,

Para Norman Calkins, o mais importante período na educação é o que decorre na aula de primeiras letras. Os que assumem, pois, o encargo de educar crianças nessa quadra da vida deviam ser especialmente aparelhados para ele, adestrados na cultura dos sentidos, peritos em ensinar coisas reais, cores e sons reais, cada qual com a palavra que os represente, hábeis, afinal em encaminhar o espírito a retificar as suas concepções. (AURAS, 2007, p. 87).

Para Calkins necessariamente primeiro vinham às coisas, depois as palavras. Segundo o autor, o maior erro didático, pedagógico e teórico promovia justamente o inverso. Assim, a escola proporcionaria condições de observar, consequentemente, de comparar e diferenciar, ampliando as ideias simples até sua complexidade. No entanto, cabia ao professor providenciar maneiras de interagir sensorialmente com os objetos, seja estes físicos e adequados a utilização, ou apenas produzidos para observação e análise.

Calkins inovou em sua transposição da teoria de Pestalozzi, porque complementoua. Além de transpor as ideias teóricas para as bancadas escolares - com uma maior aplicabilidade que o autor suíço - ampliou o campo de atividades possíveis nas Lições de Coisas. Se em outros manuais exploravam-se apenas as formas, por exemplo, o autor americano, com os mesmos objetos atingiu diferentes pontos focais de análise. Além das formas, as cores, a profundidade, a qualidade (liso, áspero, escorregadio, frágil, entre outros), os pesos, ou seja, todas as possíveis características da materialidade. Além dessa inovação, outro fator diferencial em Calkins foi seu método de ensino da leitura sob o Método Intuitivo. A memorização era rejeitada, colocando-se o processo de decifração da leitura como mais importante que o de decorar letras. A letra não deveria ser então considerada a unidade básica, visto que isoladamente não significa nada além de uma convenção, ou seja, abstração. A unidade básica é a palavra. A palavra remete a coisa. A coisa é trabalhada em exercícios, lições e análises em conjunto com a palavra. Na conhecida lição do sino, o autor promove o jogo do objeto físico, do desenho, da palavra para poder chegar a um entendimento com seus educandos sobre representação. Os alunos acabam partindo, em conjunto com o professor, de o simples ouvir de um sino ao complexo entendimento da conexão entre o material, o visual pictórico, o visual gráfico e as respectivas representatividades. Assim, Calkins de um modo geral entende que a aprendizagem deva percorrer o trajeto do concreto para o abstrato, tornando-se complexo com o passar do tempo. 
O método de Calkins, ao privilegiar a visão como o sentido mais importante para a aquisição do conhecimento escolar, submete todo e qualquer conteúdo a esse preceito e, especificamente no caso da aprendizagem da leitura, privilegia a forma da palavra e sua representação gráfica que, aliada à audição e ao tato, confluem para a escrita e para a leitura corrente. (VALDEMARIN, 2004, p. 149).

Outros teóricos no século XIX desenvolveram suas teorias ligadas a este método, tais como: Jules Paroz (1875), Fanny Ch. Delon e M. Delon (1892) e Dr. Saffray (1908).

No Brasil, o Método Intuitivo tem sua aplicabilidade a partir do final da década de 1870, com a Reforma de Leôncio de Carvalho (1879), onde fica prevista uma readequação do ensino escolar, sob uma concepção menos mnemônica e livresca, mais prática e concreta. A Reforma criou escolas noturnas para os operários, tentando burlar as normatizações excludentes que restringiam o voto aos cidadãos alfabetizados, tais como a Lei Saraiva, 1882. Ainda previa o Método Intuitivo ou Lições de Coisas em todas as escolas normais, através de suas bibliotecas e museus escolares. O livro reconhecido como referencial no Brasil, seguindo a tendência, foi Primeiras Lições de Coisas, de Norman Calkins (1886), traduzido por Rui Barbosa.

Em 1884 o próprio Imperador aprovou a publicação de Primeiras Lições de Coisas pela Tipografia Nacional, aprovando seu uso pelas escolas públicas. O livro ficou pronto em 1885 e apenas em 1886 foi iniciada sua distribuição. Segundo Phil Brian Johnson (1977), o livro foi indicado para compra pelas províncias para adoção nas escolas e distribuição aos professores primários. São Paulo e Rio Grande do Sul estariam entre as províncias a adquirirem o manual de Calkins, havendo, no entanto, carência de informações sobre a aquisição por outras províncias. Mesmo a aquisição por parte do Rio Grande do Sul ainda não foi devidamente comprovada por essa investigação. A obra traduzida por Rui Barbosa teria tido grande receptividade no meio educacional. (POSSAMAI, 2012, p. 4).

Rui Barbosa, além de traduzir Calkins lançou uma série de Pareceres (1882) que previam inúmeras modificações. Para o autor os currículos escolares deveriam ser restaurados e as ciências tornarem-se obrigatórias, assim como em outros países modernos contemporâneos. Em relação ao ensino superior os seus pareceres visavam à criação de novas instituições e novas disciplinas para os cursos de direito e medicina. Dentre as inovações na medicina a ampliação dos estudos anatômicos, anatomia comparada, sociologia e análises sobre doenças tropicais e sexualmente transmissíveis. Ainda sugeria a inclusão massiva do ensino de jardim infância, baseado em suas leituras de Froebel e Pestalozzi, visto que era nessa fase que as crianças desenvolviam sua capacidade de observação e linguagem.

Benjamin Constant, por sua vez, promoveu importante reforma educacional no ano de 1890. Constant, que acreditava que somente através da educação um povo poderia construir sua cidadania (SEKI, 2011). Entre suas principais propostas estavam: exames de 
madureza equiparados entre as instituições de ensino secundário; expedições de diplomas em sistemas de educação públicos e privados; direito de matrícula em cursos superiores. Tinha como princípios básicos a instrução popular, a liberdade, igualdade e laicidade do ensino. $\mathrm{O}$ ensino não era apenas obrigação do Estado. Benjamin Constant ainda advogava para se incutir nas escolas o método Lições de Coisas, evitando-se a exercitação mecânica e mnemônica, promovendo um ensino mais prático e concreto.

Porém, o Método Intuitivo precisava de suportes maiores do que a legislação e os livros de teóricos da educação para ser aplicado. Assim, os museus escolares formataram-se como os tradutores na prática do Método Intuitivo, trazendo a materialidade necessária para a exercitação das Lições de Coisas. Os museus escolares, aplicando o método intuitivo ou Lições de Coisas, transpondo a pedagogia do ouvir para o do olhar, visavam auxiliar o professor no ensino escolar por meio de objetos naturais (taxidermia), pedagógicos ou réplicas. Os grandes museus nacionais de ciências naturais se relacionavam diretamente com a questão educativa, cedendo seus espaços para a realização de aulas, produzindo réplicas, complementando o que era previsto nos currículos escolares, em uma relação simbiótica.

Os museus escolares, segundo Petry (2013) podem ser conceituados de seis diferentes modos, citam-se: museu escolar e pedagógico - paradoxais entre si, exercendo funções diferentes, também se localizam espacialmente em locais controversos; mиseu escolar brasileiro - versão nacional do Musée Scolaire Deyrolle; museu-armário responsável pela guarda de materiais aplicados em atividades com alunos aos moldes do método lições de coisas; museu da sala - que teria seu acervo composto de trabalhos realizados dentro do espaço da sala de aula; museu/gabinete - recolhia os materiais relevantes produzidos dentro da sala de aula; museu-associação auxiliar da escola - uniu-se a uma rede de instituições auxiliares na escola, que promoviam uma sociedade em miniatura no espaço escolar. O conceito mais aproximativo a esta pesquisa seria o museu escolar brasileiro, visto que os objetos eram em maioria importados de empresas especializadas ou profissionais específicos. A nomenclatura destes espaços apresenta-se como um ponto nevrálgico, ainda em discussão. Segundo o trabalho de Poggiani (2011) estes espaços eram conhecidos dentro das escolas, porém muitas vezes não tinham a nomenclatura de museu, podendo ser alcunhados de laboratórios ou gabinetes.

Os museus escolares eram investidos pela aquisição ou até mesmo produção de objetos para ensinar os mais variados tipos de temas. Dentre estes temas ressalto o estudo racial como um conteúdo presente em inúmeras disciplinas, tais como História Natural, 
História, Geografia e Sociologia, sendo assim preponderante a utilização de novos meios de ensino. As escolas apregoavam as teorias raciais ou racialistas, onde eram verificáveis, assim como em outros objetos de estudos, a existência de diferentes tipologias humanas. Ao ensinar sobre as diferenças entre as raças humanas, a escola se engajava em um processo de formação e amadurecimento das ideias. Como apenas livros escritos não eram mais considerados tão atrativos e efetivos, novos métodos e profissionais inovadores ganhariam terreno propício para o desenvolvimento de suas práticas. É neste panorama que os bustos tridimensionais tornam-se atrativos aos professores e institutos que quisessem inovar e ampliar a qualidade de seu ensino.

\section{MODELOS DE HISTÓRIA NATURAL: DOS INSTITUTOS CIENTÍFICOS AOS ESPAÇOS ESCOLARES}

O histórico de utilizações dos bustos em gesso, papel machê e até mesmo madeira remontam ao período da antiguidade ocidental. Já no período dos gregos antigos e romanos, os bustos eram utilizados como uma forma de glorificação e ostentação. Durante o Renascimento, os bustos mudaram seus significados. A própria escultura é considerada a arte que melhor representa o período renascentista, tamanha a importância delegada às figuras que exaltassem os aspectos humanos. Inúmeros bustos também eram produzidos com a finalidade de ornamento de tumbas em morte e exaltação das geometrias físicas em vida.

Os bustos continuariam sendo utilizados durante o Quattrocento, com a função de retrato e afirmação da personalidade do modelo, assim sendo, formadores da identidade do proponente (MANN, 2004). Donatello (1386-1466), escultor italiano, introduziu os bustos cortados no peito e sem pedestais, algo recorrente na antiguidade. Geralmente utilizava-se de terracota para a produção de suas obras. 


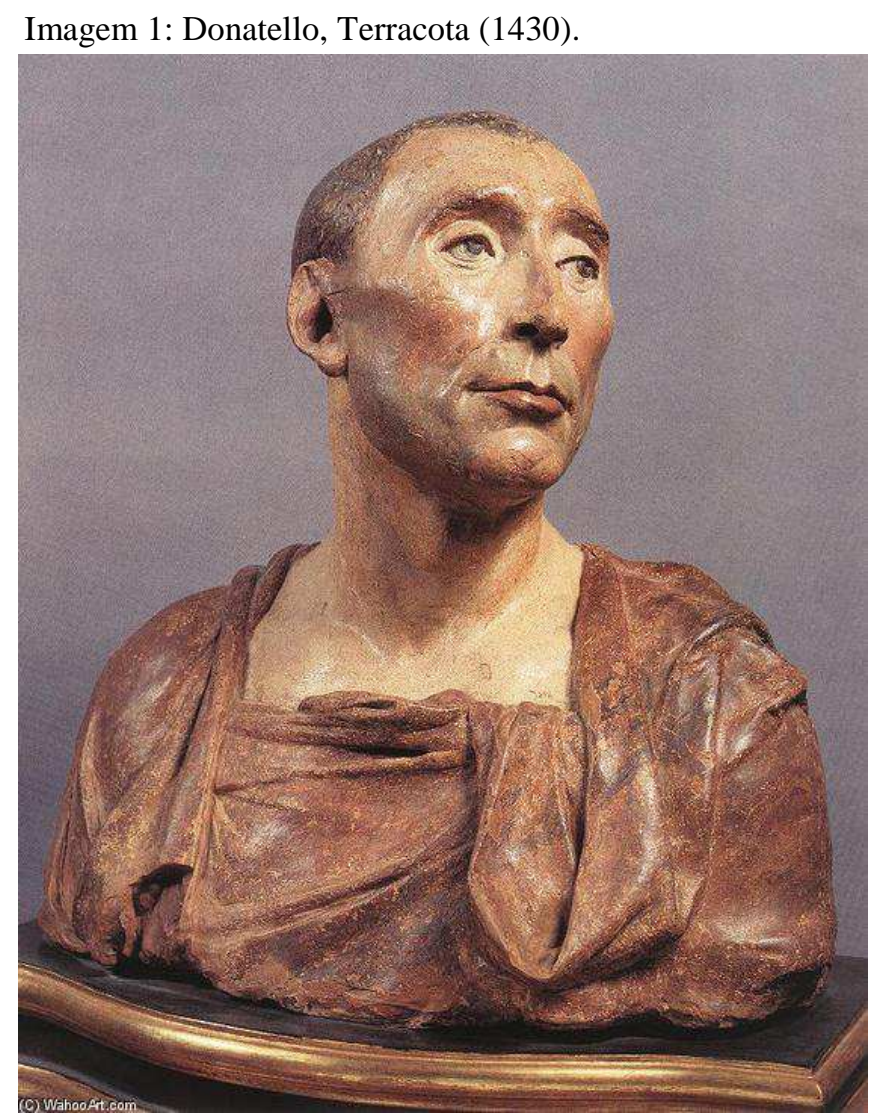

Fonte: Museo Nacionalle del Bargello (Florença) Nicollo da Uzano.

Durante o século XVI os bustos começaram a ter uma estrutura para apoio e alongavam-se até a cintura, sendo, portanto maiores que os predecessores.

No entanto, durante o século XIX estas peças específicas da arte escultórica teriam uma utilização diferenciada. No século científico, como ficou alcunhada a centúria do XIX, os estudos de expressões faciais e anatômicos utilizaram-se de bustos para seu intento (KNAUSS, 2011). Louis Rochet, escultor francês incumbido de produzir uma estátua para enaltecer D. Pedro I realizou uma série de estudos dos tipos de nativos da terra, buscando através de experimentos em gesso a melhor representação do indígena nacional. A ideia era rodear o Imperador brasileiro de doze indígenas, criando assim uma imagem fundacional. Rochet ficou tentado a pesquisar o elemento negro, um ser considerado pária na sociedade do século XIX no Brasil. Outro elemento que influenciou as relações entre imagem tridimensional e os estudos raciais foi a proximidade de Louis Rochet com a Antropologia Física. Seu irmão, Charles Rochet, antropólogo e grande divulgador de suas obras, teria cooptado alguns de seus estudos em gesso para a discussão racial. Em conferências na Sociedade de Antropologia de Paris consta que Charles Rochet teria informado a intensa produção do irmão realizada no Brasil. As características físicas são escritas de maneira 
detalhada no catálogo do artista, tendo referências ao tipo de nariz, aos lábios, cabelos entre outros. Com este apreço pelos estudos tipológicos humanos, inseriu-se no contexto de seu século, atento às questões étnico-raciais, tanto no campo artístico, quanto no científico.

Durante o século XIX, a doutrina Positivista de Auguste Comte também tinha um projeto sobre o papel que as artes exerceriam em meio à sociedade. As artes, inclusive a escultórica, tinham o papel de manutenção do passado e de conexão com o futuro. Assim:

No texto Aptitude Esthétique, apenas em uma rápida frase, Comte conceitua o que é
arte e para que serve: "Consiste sempre em uma representação ideal daquilo que é,
destinada a cultivar nosso instinto da perfeição". Para ele, mais importante que
reproduções fiéis da realidade está a idealização de tipos, figuras exemplares que
contribuíram para o bem da Humanidade. (LEAL, 2006, p. 44).

A introdução de modelos ideais serviria de guia para o alcance destes modelos em meio natural. Sejam quais fossem as representações, pictóricas, escultóricas ou alegóricas, estas teriam o papel de fonte inspiradora. Embora pareçam imaginativas e utópicas, estas sensações seriam pensadas racionalmente pelos orgãos governamentais, que gerenciariam estas sensações junto a população.

Devido ao contexto político e social do mundo, preocupado com as questões raciais e com bases científicas que justificassem as dominações imperialistas de Ásia e África, os bustos ganhariam novas funções, sejam ligadas aos institutos de pesquisa científica em Antropologia, ou como parte integrante de projetos político-sociais como os de Comte, visando hierarquizar a sociedade. Porém, a entrada destes objetos nas escolas surgiu através dos museus de História Natural, que mantinham amplo debate com o campo antropológico. Os museus de História Natural iniciaram durante o século XIX intensa pesquisa craniométrica e racial através de réplicas ou de modelos originais. Um exemplo que estes objetos tornaramse usuais para o estudo dos tipos raciais humanos pode ser visto pelo acervo do museu de Coimbra. Segundo Amaral (2011), estes bustos de papel machê foram adquiridos pela Universidade para o estudo das diversificadas fenotipias humanas. Nota-se a representação dos tipos raciais "puros" ou ideais, livres de toda e qualquer miscigenação. Os tipos representados são: Zulu, Índio norte-americano, caucasiano e mongol. 
Imagem 2: Bustos do Museu de História Natural de Coimbra, 1893.
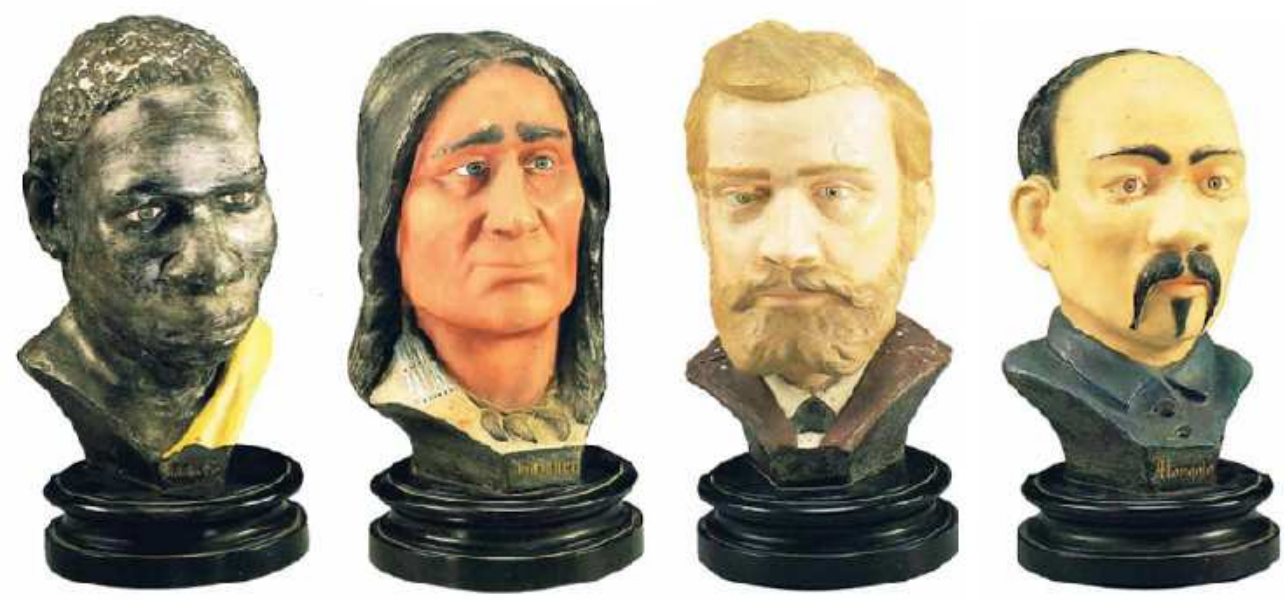

Fonte: Site oficial do Museu de História Natural de Coimbra.

Os museus de História Natural no Brasil também estudavam sobre as raças humanas na transição do século XIX para o XX. Os casos mais notáveis são os relacionados com eventos sobre a temática como a Exposição de Antropologia de 1882, realizado no Museu Nacional no Rio de Janeiro, o Congresso Internacional das raças de 1911, também no Museu Nacional, além das publicações realizadas pelo corpo diretivo dos museus Emílio Goeldi e do Museu Paulista. Estas instituições mantinham diálogo com outros museus e institutos de pesquisa europeus e americanos, inclusive promovendo a permuta de peças de estudos como crânios e réplicas de nativos e demais raças que fossem interessantes aos estudos.

Como os museus nacionais brasileiros mantinham comunicação ativa com escolas, a temática dos tipos raciais não tardaria a ser acoplada aos currículos como uma grande inovação. Valendo-se dos incentivos à adoção do Método Intuitivo, essencialmente sensorial, a materialidade de bustos poderia ser considerada uma tecnologia do ensino necessária. Nos currículos do Colégio Pedro II foram verificadas algumas referências ao estudo racial com imagens, inclusive com a presença de crânios e réplicas, mas não a referência direta da existência de bustos em gesso.

\section{BUSTOS RACIAIS DO MUSEU DO INSTITUTO SÃO JOSÉ E DO MUSEU METODISTA}

Ambas as escolas pesquisadas em minha dissertação, onde analiso todas as imagens utilizadas para o ensino dos tipos raciais humanos, possuem bustos componentes de diferentes 
fenotipias, utilizadas em diferentes disciplinas escolares na temática racialista. Embora com trajetórias diversas as duas instituições fundaram seus museus escolares em datas aproximadas e com uma missão voltada principalmente aos estudos das ciências biológicas.

O Colégio Metodista Americano de Porto Alegre, fundada em 19 de outubro de 1885 por Dr. João Correa e a professora Carmen Chacon, originário dos Estados Unidos, veio fixar suas bases no Rio Grande do Sul através do Uruguai. Como o analfabetismo era extremo no Rio Grande do Sul, os metodistas focaram no processo de escrita e leitura seus maiores investimentos. O projeto era liberal e moderno, totalmente de acordo com os ideais positivistas de desoneração do erário público com a educação. As peças que existem até os dias de hoje transitaram por dois espaços museais da instituição: O museu do Ipa College, fundado na década de 1920, e o museu do colégio americano, fundado em 1931. Os sete bustos encontrados no museu escolar do Colégio Metodista Americano foram utilizados pela congregação confessional para o ensino desde a década de 1920. Os bustos são produzidos em gesso e/ou papel machê, tendo a sua superfície coberta por uma espécie de tinta sintética. A estrutura das cabeças busca ter um caráter fidedigno aos rostos humanos. Dos bustos representativos das raças humanas podemos avistar uma tentativa de criar os esteriótipos do hindu, o negro australiano, o negro zulu, o chinês, o índigena norte-americano e o caucasiano, todos em seu formato puro e ideal. Nem mesmo nos currículos institucionais havia referências a ideia de raça brasileira.

Nenhum documento institucional registra o produtor dos bustos, nem mesmo a data exata de sua aquisição. No entanto, as peças continuariam sendo utilizadas pelo museu como estratégias de ensino dos tipos raciais até o final da década de 1950. 
Imagem 3: Bustos raciais do Museu Escolar Metodista.

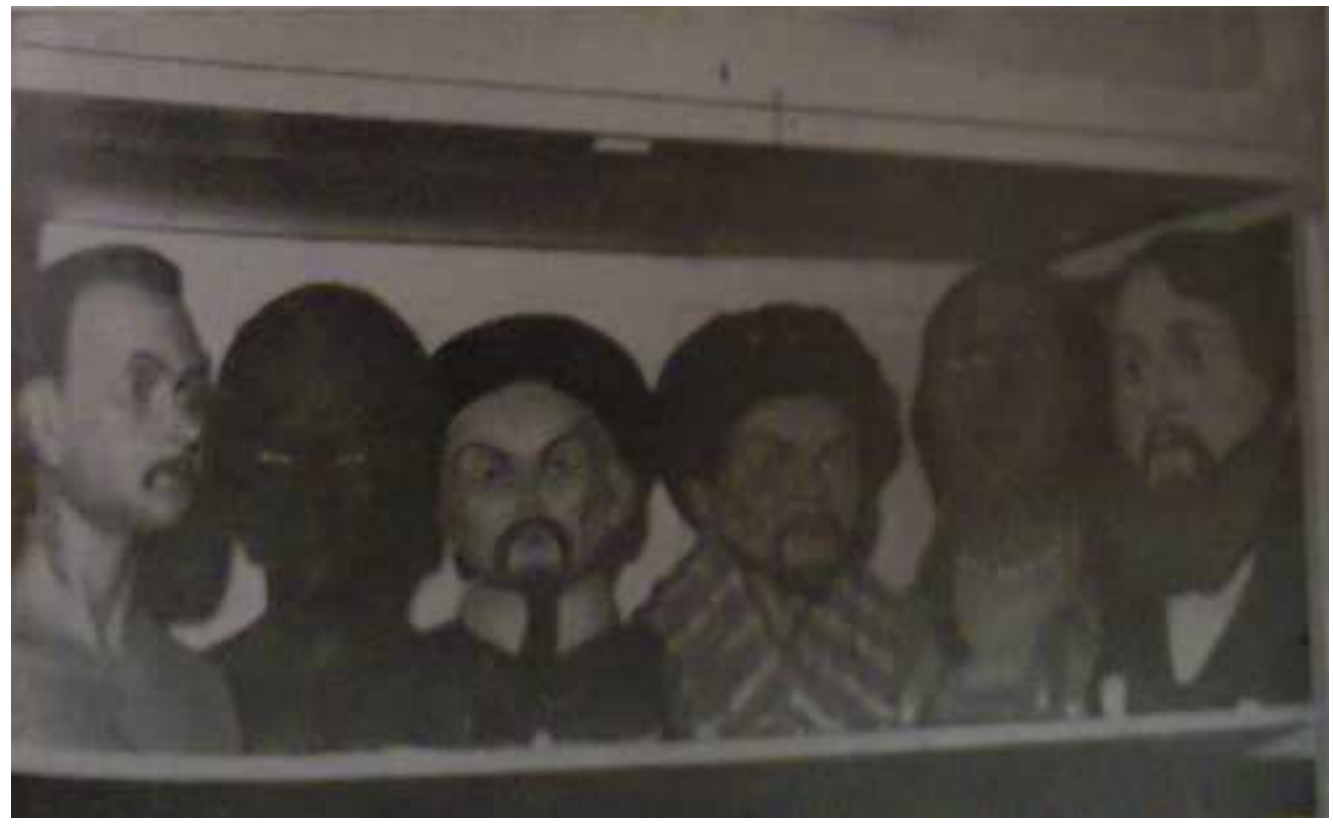

Fonte: Revista Colunas, Volume I, número 1, 1961.

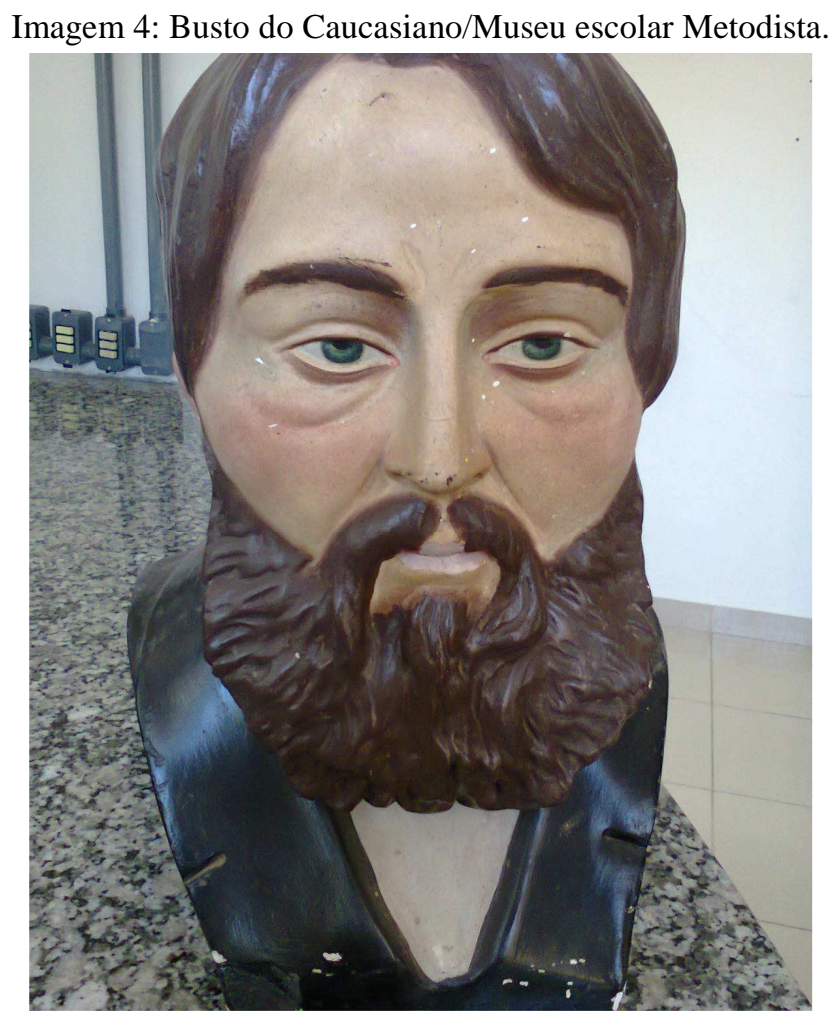

Fonte: Acervo Pessoal (Museu Escolar Metodista).

Por sua vez, o Instituto São José, fundado pela congregação dos irmãos Lasallistas em 1908 iniciou seu projeto ligado à ideia da fundação de uma escola de agronomia. Posteriormente, em 1926, a instituição investiu na criação de laboratórios, salas temáticas e 
museus. A intenção era possuir uma escola normalista, a especialidade dos Lasallistas em formar professores.

Na década de 1930, as primeiras referências aos bustos de gesso e/ou papel machê são feitas nos documentos institucionais, que juntamente aos impressos dos livros e compêndios escolares e projetáveis do cinematógrafo, contribuiriam para a modernização do ensino sobre as raças. Os currículos de História Natural, Geografia, História, Sociologia e Biologia previa a utilização de novas tecnologias de ensino, além de possuírem especificamente a temática de estudos dos tipos raciais. Estes apareciam descritos de inúmeras maneiras e nos mais diversificados níveis de graduação.

Os bustos Lasallistas eram cinco: caucasiano, Chinês, Cafre-Zulu, Australiano e Índio norte-americano. Há que se notar que os bustos do museu escolar Lasallista não possuem ombros e nem mesmo roupagens. Alusões à questão cultural podem ser notadas no trato com os cabelos e demais pelagens do rosto, além de algum adorno qualquer. A localização das peças transitava entre as salas especializadas de geografia e o museu, que tinha por maior interesse a História Natural. A primeira referência das peças remonta o princípio da década de 1930, sendo adquiridas junto a uma empresa de Porto Alegre. Os bustos continuaram sendo utilizados como recursos de ensino até o princípio da década de 1950.

Imagem 5: Bustos raciais do Museu escolar Lasallista.

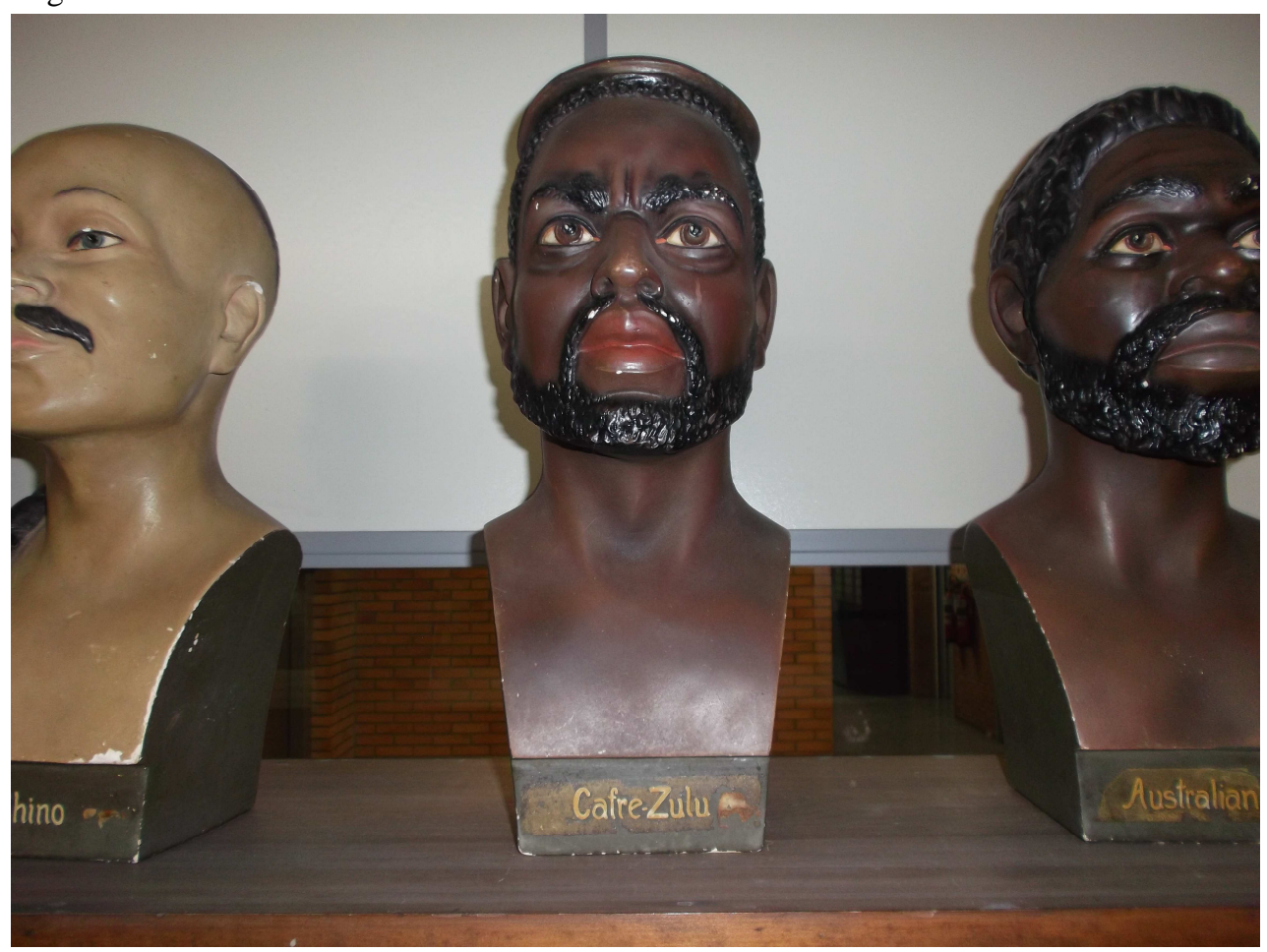

Fonte: Acervo Pessoal (Museu e Arquivo Histórico La Salle). 


\section{CONCLUSÕES PARCIAIS}

As conclusões deste artigo ainda são preliminares, visto que a escrita da dissertação de mestrado, responsável pelo surgimento deste escrito ainda se encontra em fase de análise de seu corpus empírico. No entanto, alguns apontamentos podem ser mencionados a guisa de conclusão.

Em primeiro lugar, devemos compreender que os bustos, enquanto objetos materiais sofreram um processo de ampla significação durante os tempos. De símbolos de poder, identidade e afirmação durante a antiguidade e Renascimento ocidental até peças de estudos científicos. Estes modelos tornaram-se necessários ao estudo da própria essência e origem humana. A figura tridimensional foi entendida como uma tecnologia para institutos e museus especializados compreenderem as diferentes fenotipias humanas.

Por outro lado, estes objetos entraram para os espaços escolares não apenas pela influência exercida pelos adeptos do Método Intuitivo, mas devido ao fato de existir uma demanda social e política, que desejava que ensino dos tipos raciais humanos fosse uma temática trabalhada nas escolas nacionais. A influência positivista e cientificista da transição do século XIX para o XX foi fulcral para que este tema tivesse espaço nos currículos das principais escolas, principalmente as formadoras de professores.

Por fim, devemos compreender que estes objetos na atualidade fazem parte da memória escolar, aparatos pedagógicos que nos dias de hoje não tem mais a serventia didática, embora ainda possam ser agentes educativos no momento em que foram ressignificadas e realocados nos renovados museus escolares, agora voltados à memória da educação.

\section{REFERÊNCIAS}

AMARAL, Raquel Filipa de Almeida. Modelos Didáticos na Museologia e Ensino da Botânica na Universidade de Coimbra. 2011. 148 f. Tese (Doutorado em Educação). Universidade de Coimbra, Coimbra.

AURAS, Gladys Mary Teive. Manual de lições de coisas de Norman Calkins: operacionalizando a forma intuitiva de ensinar e de aprender. Sarmiento, Florianópolis: UFSC, núm. 11, p. 79-92, 2007.

KNAUSS, Paulo. Imaginação escultórica e identidade étnica no século XIX: O negro Horácio, de Louis Rochet, entre a França e o Brasil. XXXI Colóquio CBHA, 2011 [Com/Con]tradições na História da Arte. São Paulo, UNICAMP, 2011. 
LEAL, Elisabete. Os Filósofos em Tinta e Bronze: Arte, Positivismo e Política na obra de Décio Villares e Eduardo de Sá. 2006. 299 f. Tese (Doutorado em HistóriaUniversidade Federal do Rio de Janeiro, Rio de Janeiro.

MANN, Nicholas. O Renascimento. Londres: Folio, 2004, 255 f.

PETRY, Marilia Gabriela. Da recolha à exposição: a constituição de museus escolares em escolas públicas primárias de Santa Catarina (Brasil - 1911 a 1952). 2012. 222f. Dissertação (Mestrado em Educação). Universidade do Estado de Santa Catarina Florianópolis.

POGGIANI, Ana Maria L. Os museus escolares na primeira metade do século XX: Sua importância na educação brasileira. 2011. 109 f. Dissertação (Mestrado em Educação). Universidade Católica de Santos, Santos.

POSSAMAI, Zita Rosane. "Lição de coisas" no museu: o método intuitivo e o Museu do Estado do Rio Grande do Sul, Brasil, nas primeiras décadas do século XX. Arquivos Analíticos de Políticas Educativas, Tempe: Arizona State University, volume 20, número 43, p.1- 16, 2012.

VALDEMARIN, Vera Teresa. Estudando as Lições de Coisas. Campinas, Autores Associados, 2004, $187 \mathrm{f}$.

SEKI, Ariele. A Disciplina de Instrução Moral e Cívica na Reforma educacional de Benjamin Constant de 1890. Revista Histedbr, Campinas, p. 1-21, 2011. 